\title{
Pengaruh Terpaan Iklan di Media Sosial Youtube terhadap Persepsi Konsumen (Studi terhadap Pelanggan Iklan Tiket.com di Youtube)
}

\author{
Rachel Febrida, Roswita Oktavianti \\ devotarachel18@gmail.com,roswitao@fikom.untar.ac.id \\ Fakultas Ilmu Komunikasi Tarumanagara
}

\begin{abstract}
Advertising becomes a very important promotional instrument, especially for companies that promote goods and services to the public. One form of advertising that the companies do is advertising exposure. Exposure can be interpreted as activity of hearing, seeing, and reading messages from the media or having an experience and attention to messages that happen to individuals or groups. Advertising exposure on youtube can build consumer's perception. Perception is the process where consument choose, organize, and asume information to create a picture of life. This research wants to find out whether there is an influence of advertising exposure on social media especially Youtube on consumer's perception. This research uses a survey method by distributing online questionnaires to 100 respondents. This research conducts research on Tiket.com customers who watch advertisements on Youtube. The results of this research is the effect of advertising exposure on social media Youtube on consumer's perception. The advertisement has an influence on consumer perception by $34 \%$, the remaining $66 \%$ is influenced by variables not examined in this research.
\end{abstract}

Keywords: advertising exposure, consumer perception, social media

\begin{abstract}
Abstrak
Iklan telah menjadi salah satu promosi yang penting, terutama untuk perusahaan yang mempromosikan barang atau jasa kepada masyarakat luas. Salah satu yang dapat dilakukan perusahaan dengan cara menggunakan terpaan iklan. Terpaan dapat diartikan sebagai kegiatan mendengar, melihat, dan membaca pesan-pesan media ataupun mempunyai pengalaman dan perhatian terhadap pesan tersebut yang dapat terjadi pada individu atau kelompok. Iklan yang muncul bertubi-tubi pada Youtube menimbulkan munculnya persepsi pada konsumen. Persepsi adalah proses dimana individu memilih, mengorganisasi, dan mengartikan masukan informasi untuk menciptakan suatu gambaran tentang kehidupan. Tujuan dari penelitian ini adalah untuk mengetahui pengaruh terpaan iklan di media sosial Youtube terhadap persepsi iklan. Metode survei adalah metode yang digunakan dalam penelitian ini dengan menyebarkan kuesioner online kepada 100 sampel responden. Penelitian ini menunjukkan bahwa ada pengaruh terpaan iklan di media sosial Youtube terhadap persepsi konsumen. Terpaan iklan memiliki pengaruh terhadap persepsi konsumen sebesar 34\%, sisanya 66\% dipengaruhi oleh variabel lain yang tidak diteliti dalam penelitian ini.
\end{abstract}

Kata Kunci: Terpaan Iklan, Persepsi Konsumen, Media Sosial

\section{Pendahuluan}

Komunikasi merupakan pertukaran informasi terhadap dua orang atau lebih yang akan membentuk pengertian pada setiap masing-masing orang (Hafied, 2016). Dalam komunikasi terdapat unsur-unsur komunikasi yaitu pengirim/sumber (source), pesan (message), saluran/media (channel), penerima (receiver), dan akibat/pengaruh 
(effect). Komunikasi dibagi dalam beberapa kategori, salah satunya adalah komunikasi persuasif. Komunikasi persuasif memiliki beberapa tujuan yaitu memberikan pemahaman kepada konsumen, membujuk konsumen untuk membeli produk, memperkenalkan produk agar mudah dipahami (Putri, 2016).

Bentuk komunikasi persuasif adalah iklan. Iklan dapat diartikan sebagai bentuk komunikasi nonpersonal tentang organisasi, produk atau jasa, dan ide. Iklan menjadi strategi promosi yang sangat penting, terutama untuk perusahaan yang ingin barang atau jasanya dikenal oleh masyarakat. Banyak perusahaan lebih memilih iklan dipasang pada media massa agar barang atau jasanya diketahui banyak orang karena iklan pada media massa dianggap efisien karena biaya yang minim dan mendapatkan audiens yang banyak (Morissan, 2012).

Salah satu cara melakukan promosi adalah dengan cara terpaan iklan. Menurut Ardianto (dalam Munawwaroh, 2018) terpaan artinya keadaan masyarakat terkena pesan yang banyak yang disebarluaskan pada media sosial. Terpaan dapat diartikan sebagai kegiatan mendengar, melihat, dan membaca pesan di media ataupun mempunyai perhatian terhadap pesan tersebut yang dapat terjadi pada individu atau kelompok.

Terpaan iklan banyak dilakukan pada internet khususnya media sosial. Media sosial adalah sebuah aplikasi website yang bisa menciptakan komunikasi yang dapat membuat orang menjadi berinteraksi dalam kelompok. Media sosial sudah menjadi bagian dari e-marketing strategy. Media sosial mencakup Facebook, Instagram, Twitter, Youtube, Blog, dan lain-lain (Puntoadi, 2011).

Menurut Rosengren (dalam Haliem, Farid dan Utami, 2018) terpaan iklan dapat diukur melalui 3 dimensi, yang pertama adalah frekuensi, yaitu rutinitas atau seberapa sering orang menggunakan media dan mengerti akan pesan yang disampaikan. Kedua adalah atensi, yaitu ketertarikan pada seseorang dalam memanfaatkan media dan mengonsumsi pesan yang terdapat pada media. Ketiga adalah durasi, yaitu seberapa lama orang memakai media untuk mengerti dan mendapat pesan dari media tersebut.

Berkembangnya teknologi pada media sosial Youtube membuat banyak perusahaan melakukan terpaan iklan pada Youtube yang pada akhirnya menimbulkan persepsi dari konsumen yang terkena terpaan iklan. Persepsi adalah proses dimana seseorang memilih, mengorganisasi, dan mengartikan masukan pesan untuk menciptakan suatu gambaran tentang kehidupan (dalam Saputra dan Samuel, 2013).

Persepsi dibagi atas 3 proses yaitu perhatian selektif, distorsi selektif dan ingatan selektif. Perhatian selektif adalah seseorang menerima banyaknya rangsangan setiap hari (dibanjiri iklan), dari banyaknya rangsangan itu maka seseorang secara otomatis akan menyaring pesan yang didapatnya. Distorsi selektif adalah seseorang mengarahkan suatu informasi agar sesuai dengan pemikiran kita. Ingatan Selektif merupakan seseorang akan menghapus ingatan mereka tentang banyak hal yang mereka pelajari, tapi akan memikirkan atau mengingat informasi yang mereka yakini (Kotler dan Keller, 2009)

Tiket.com adalah salah satu Online Travel Agent (OTA) yang menggunakan media sosial Youtube untuk melakukan kegiatan promosi iklan dengan cara memberikan terpaan iklan kepada konsumennya. Tiket.com merupakan salah satu web yang memfasilitasi jasa travelling khususnya layanan pemesanan tiket penerbangan dan pemesanan hotel (diakses dari www.swa.co.id pada tanggal 11 September 2019 pukul 21.38). Tujuan penelitian ini untuk mengetahui adakah pengaruh terpaan iklan di media sosial Youtube terhadap persepsi konsumen. 
Rachel Febrida: Pengaruh Terpaan Iklan di Media Sosial Youtube terhadap Persepsi Konsumen (Studi terhadap Pelanggan Iklan Tiket.com di Youtube)

\section{Metode Penelitian}

Dalam penelitian ini, penulis menggunakan metode penelitian kuantitatif dengan metode survei. Metode survei ini mendapatkan data dari tempat tertentu yang alamiah seperti mengumpulkan data dengan cara menyebarkan kuesioner, tes, dan wawancara (Sugiyono, 2017).

Penulis menggunakan metode pengumpulan data kuesioner yang disebarkan dengan google form. Populasi yang digunakan untuk penelitian ini adalah seluruh pelanggan Tiket.com yang menggunakan Youtube serta peneliti menggunakan 100 sampel responden. Teknik pengambilan sampel yang digunakan peneliti adalah nonprobability sampling yaitu teknik pengambilan sampel yang tidak memperkenankan setiap orang diberi kesempatan yang sama yang pada akhirnya dipilih menjadi sampel (Sugiyono, 2017). Dalam pengukuran penelitian ini menggunakan skala likert. Untuk membantu penulis dalam memperoleh data responden, uji validitas dan uji reliabilitas maka penulis menggunakan program SPSS.

\begin{tabular}{|c|c|}
\hline Terpaan Iklan & \\
Frekuensi & Persepsi \\
Atensi & Perhatian \\
Durasi & Distorsi \\
$(\mathrm{X})$ & Ingatan \\
& $(\mathrm{Y})$ \\
\hline
\end{tabular}

H0: Terpaan iklan di media sosial Youtube tidak memiliki pengaruh terhadap persepsi konsumen

H1: Terpaan iklan di media sosial Youtube memiliki pengaruh terhadap persepsi konsumen

\section{Hasil Penemuan dan Diskusi}

Dalam penelitian ini, penulis menyebarkan kepada 100 responden dan mendapatkan data berdasarkan jenis kelamin, sebanyak 45 responden atau sebesar $45 \%$ adalah berjenis kelamin laki-laki dan sebanyak 55 responden atau setara dengan $55 \%$ adalah berjenis kelamin perempuan. Sedangkan berdasarkan usia, sejumlah 15 responden atau setara $15 \%$ berusia dibawah 20 tahun, sejumlah 56 responden atau setara 56\% berusia 21-30 tahun, sejumlah 4 responden atau setara $4 \%$ berusia $31-40$ tahun, sejumlah 15 responden atau setara $15 \%$ berusia 41-50 tahun, dan sejumlah 10 responden atau setara $10 \%$ berusia di atas 50 tahun.

Setelah melalui proses pengolahan data menggunakan SPSS versi 15, maka berikut adalah hasil uji validitas.

Tabel 1. Uji Validitas

\begin{tabular}{cclcc}
\hline Variabel & Butir & \multicolumn{1}{c}{ Indikator } & $\begin{array}{c}\text { Corrected Item- } \\
\text { Total Correlation }\end{array}$ & Keterangan \\
\hline Terpaan Iklan & TI1 & $\begin{array}{l}\text { Anda menggunakan media } \\
\text { sosial Youtube }\end{array}$ & 0,323 & Valid \\
\hline
\end{tabular}




\begin{tabular}{|c|c|c|c|c|}
\hline & TI2 & $\begin{array}{l}\text { Anda melihat iklan pada } \\
\text { media sosial Youtube }\end{array}$ & 0,492 & Valid \\
\hline & TI3 & $\begin{array}{l}\text { Anda menonton atau melihat } \\
\text { iklan Tiket.com di Youtube }\end{array}$ & 0,599 & Valid \\
\hline & TI4 & $\begin{array}{l}\text { Anda menonton iklan } \\
\text { Tiket.com di Youtube dan } \\
\text { mengerti pesan dari iklan }\end{array}$ & 0,669 & Valid \\
\hline & TI5 & $\begin{array}{l}\text { Anda memperhatikan adegan } \\
\text { dalam iklan Tiket.com di } \\
\text { Youtube }\end{array}$ & 0,669 & Valid \\
\hline & TI6 & $\begin{array}{l}\text { Anda menikmati music pada } \\
\text { iklan Tiket.com di Youtube }\end{array}$ & 0,581 & Valid \\
\hline & TI7 & $\begin{array}{l}\text { Anda menonton iklan } \\
\text { Tiket.com } 5 \text { detik lalu skip } \\
\text { ad (melewati iklan) }\end{array}$ & 0,036 & Tidak Valid \\
\hline & TI8 & $\begin{array}{l}\text { Anda menonton iklan } \\
\text { Tiket.com sampai habis }\end{array}$ & 0,550 & Valid \\
\hline & TI9 & $\begin{array}{l}\text { Setelah menonton iklan } \\
\text { Tiket.com sampai habis, } \\
\text { Anda menonton ulang iklan } \\
\text { tersebut }\end{array}$ & 0,406 & Valid \\
\hline \multirow[t]{6}{*}{$\begin{array}{l}\text { Persepsi } \\
\text { Konsumen }\end{array}$} & PK1 & $\begin{array}{l}\text { Anda memperhatikan iklan } \\
\text { Tiket.com karena sedang } \\
\text { mencari tiket }\end{array}$ & 0,716 & Valid \\
\hline & PK2 & $\begin{array}{l}\text { Anda memperhatikan iklan } \\
\text { Tiket.com karena adanya } \\
\text { potongan atau diskon yang } \\
\text { diinformasikan dalam iklan }\end{array}$ & 0,719 & Valid \\
\hline & PK3 & $\begin{array}{l}\text { Anda memperhatikan iklan } \\
\text { Tiket.com karena adegan dan } \\
\text { music yang menarik pada } \\
\text { iklan }\end{array}$ & 0,666 & Valid \\
\hline & PK4 & $\begin{array}{l}\text { Meyakini bahwa Tiket.com } \\
\text { merek terbaik disbanding } \\
\text { Online Travel Agent (OTA) } \\
\text { lainnya }\end{array}$ & 0,619 & Valid \\
\hline & PK5 & $\begin{array}{l}\text { Munculnya iklan Tiket.com } \\
\text { di Youtube membuat anda } \\
\text { mengingat iklan tersebut }\end{array}$ & 0,617 & Valid \\
\hline & PK6 & $\begin{array}{l}\text { Munculnya iklan Tiket.com } \\
\text { di Youtube membuat anda } \\
\text { memahami iklan Tiket.com } \\
\text { dibanding iklan lain }\end{array}$ & 0,732 & Valid \\
\hline
\end{tabular}

Berdasarkan Tabel 1, maka dapat disimpulkan bahwa butir-butir pernyataan di atas seluruh variabel dinyatakan 14 pernyataan valid karena mempunyai angka korelasi diatas 0,2 dan 1 pernyataan tidak valid dikarenakan mempunyai angka 
Rachel Febrida: Pengaruh Terpaan Iklan di Media Sosial Youtube terhadap Persepsi Konsumen (Studi terhadap Pelanggan Iklan Tiket.com di Youtube)

korelasi dibawah 0,2 . Selanjutnya butir pernyataan yang tidak valid, tidak dilanjutkan dalam analisis.

Tabel 2. Uji Reliabilitas

\begin{tabular}{lcc}
\hline \multicolumn{1}{c}{ Variabel } & Cronbach's Alpha & Keterangan \\
\hline Terpaan iklan & 0,791 & Reliabel \\
\hline Persepsi Konsumen & 0,863 & Reliabel \\
\hline
\end{tabular}

Sumber: Data Diolah dari Kuesioner

Berdasarkan Tabel 2, hasil uji reliabilitas menyatakan maka variabel terpaan iklan dan persepsi konsumen reliabel karena memiliki angka lebih besar dari 0,6. Dalam variabel terpaan iklan dapat terlihat memiliki nilai Cronbach's Alpha sebesar 0,791 dan dalam variabel persepsi konsumen dapat terlihat memiliki nilai Cronbach's Alpha sebesar 0,863, maka dengan demikian kedua variabel ini dinyatakan reliabel.

Tabel 3. Uji Koefisien Korelasi dan Determinasi

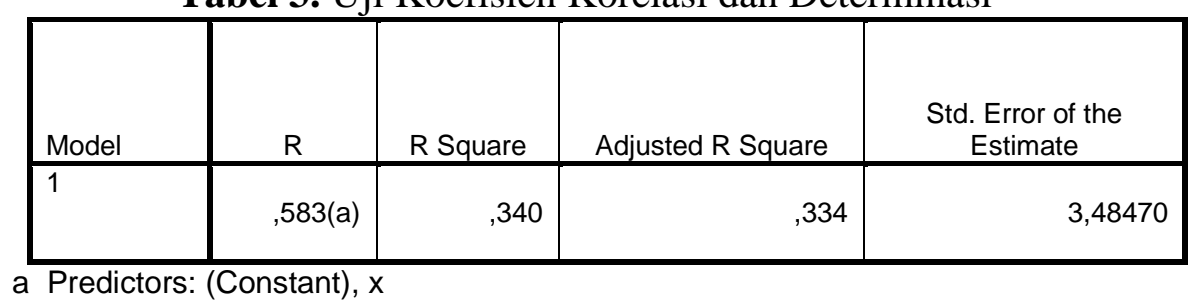

Sumber: Data Diolah dari Kuesioner

Berdasarkan Tabel 3, diketahui hasil dari uji koefisien korelasi (R) variabel X (terpaan iklan) terhadap variabel $\mathrm{Y}$ (persepsi konsumen) dalam penelitian ini dinyatakan cukup karena sebesar 0,583 yang berada pada rentang $0,40-0,599$. Dapat disimpulkan bahwa terpaan iklan terhadap persepsi konsumen terdapat hubungan dan kekuatan hubungan tersebut adalah cukup. Sifat hubungan dari penelitian ini adalah positif, sehingga apabila variabel $\mathrm{X}$ (terpaan iklan) meningkat maka variabel $\mathrm{Y}$ (persepsi konsumen) juga meningkat. Sebaliknya apabila variabel $X$ (terpaan iklan) menurun maka variabel Y (persepsi konsumen) juga akan menurun.

Hasil uji determinasi dari $\mathrm{R}$ square adalah 0,340, dapat juga disimpulkan bahwa persepsi konsumen terhadap iklan Tiket.com di Youtube dipengaruhi sebesar $34 \%$ oleh terpaan iklan, sementara $66 \%$ sisanya dikuasai oleh variabel lainnya yang tidak dimasukan ke dalam model penelitian ini.

Tabel 4. Uji Analisis Regresi Linier Sederhana

\begin{tabular}{|c|c|c|c|c|c|c|}
\hline \multirow[b]{2}{*}{ Mode } & & \multicolumn{2}{|c|}{$\begin{array}{l}\text { Unstandardized } \\
\text { Coefficients }\end{array}$} & \multirow{2}{*}{$\begin{array}{l}\text { Standardized } \\
\text { Coefficients } \\
\text { Beta }\end{array}$} & \multirow{2}{*}{$\mathrm{t}$} & \multirow{2}{*}{$\begin{array}{l}\text { Sig. } \\
\text { Std. Error }\end{array}$} \\
\hline & & $B$ & Std. Error & & & \\
\hline & (Constant) & 15,244 & 1,105 & & 13,793 & ,000 \\
\hline & $y$ &, 578 & ,081 &, 583 & 7,112 & ,000 \\
\hline
\end{tabular}

Sumber: Data Diolah dari Kuesioner 
Persamaan pada Tabel 4, dapat disimpulkan sebesar 15,244 mengatakan bahwa konstanta dari fungsi regresi yang memperlihatkan jika tidak ada kenaikan pada variabel X (terpaan iklan), maka pada variabel Y (persepsi konsumen) akan mencapai 15,244. Maka setiap ada kenaikan satu (1) angka atau perubahan variabel X (terpaan iklan), maka variabel Y (persepsi konsumen) akan mendapati kenaikan sebesar 0,578.

Nilai sig pada penelitian ini adalah $0,000<0,05$, dengan itu dapat disimpulkan bahwa terpaan iklan berdampak signifikan terhadap persepsi konsumen yang artinya yaitu hasil dari penelitian ini tidak hanya berlaku pada sampel tetapi juga berlaku pada populasi.

Nilai $t_{\text {tabel }}$ variabel $X$ sebesar 1,987 dan nilai thitung variabel $X$ sebesar 7,112. Maka $T_{\text {hitung }}>\mathrm{T}_{\text {tabel }}$ yaitu 7,112 $>1,987$ yang artinya dapat dikatakan hasil uji $\mathrm{T}$ pada variabel $\mathrm{X}$ adalah $\mathrm{H} 0$ ditolak dan $\mathrm{H} 1$ diterima. Hal ini dapat dikatakan terdapat pengaruh terpaan iklan terhadap persepsi konsumen.

\section{Simpulan}

Berdasarkan hasil penelitian yang telah diperoleh penulis, terdapat hubungan antara terpaan iklan di media sosial Youtube terhadap persepsi konsumen. Hubungan dalam penelitian ini dinyatakan cukup dan bernilai positif sehingga apabila terpaan iklan meningkat maka persepsi konsumen juga akan meningkat.

Penelitian ini menyatakan $\mathrm{H} 0$ ditolak sedangkan $\mathrm{H} 1$ diterima. Dalam penelitian ini terdapat pengaruh terpaan iklan di media sosial Youtube terhadap persepsi konsumen.Terpaan iklan memiliki pengaruh terhadap persepsi konsumen sebesar $34 \%, 66 \%$ sisanya dipengaruhi oleh variabel lainnya yang tidak teliti dalam penelitian ini.

\section{Ucapan Terima Kasih}

Penulis mengungkapkan rasa terima kasih kepada seluruh responden yang meluangkan waktu dan membantu serta memberi dukungan hingga penelitian ini dapat berjalan dengan baik dan lancar.

\section{Daftar Pustaka}

Hafied. (2016). Pengantar Ilmu Komunikasi. Jakarta : Rajawali Pers..

Haliem, Putri., Farid., dan Budi, Utami. (2018). Pengaruh Terpaan Media Line Webtoon "Wonderwall" Terhadap Opini Pembaca Mengenai Isu Kesehatan Mental. Koneksi, Vol.2, No 2.

Kotler, Philip., dan Keller, Lane. (2009). Manajemen Pemasaran. Jakarta : Macanan Jaya Cemerlang.

Morissan. (2017). Periklanan Komunikasi Pemasaran Terpadu. Jakarta : Kencana Prenada Media

Munawaroh, Putri. (2018). Pengaruh Terpaan Media Pada Akun Instagram @Exploresiak Terhadap Minat Kunjungan Wisata ke Siak Sri Indrapura. JOM FISIP Vol. 5 No. 1.

Puntoadi, Danis. (2011). Menciptakan Penjualan Melalui Sosial Media. Jakarta : PT. Elex Komputindo.

Putri, Primadhany. (2016). Aplikasi Pendekatan-Pendekatan Persuasif Pada Riset Komunikasi Pemasaran : Iklan Melibatkan Penciptaan dan Penerimaan Pesan 
Rachel Febrida: Pengaruh Terpaan Iklan di Media Sosial Youtube terhadap Persepsi Konsumen (Studi terhadap Pelanggan Iklan Tiket.com di Youtube)

Komunikasi Persuasif Mengubah Perilaku Pembelian. The Messenger, Vol.3, No.1.

Saputra, Rico., dan Samuel, Hatane. (2013). Analisa Pengaruh Motivasi, Persepsi, Sikap Konsumen Terhadap Keputusan Pembelian Mobil Daihatsu Xenia di Sidoarjo. Jurnal Manajemen Pemasaran Vol. 1, No.1.

Sugiyono. (2017). Metode Penelitian Kuantitatif, Kualitatif, dan R\&D. Bandung : Alfabeta 